\title{
HEIDEGGER Y LA BIOLOGÍA: MECANICISMO Y VITALISMO EN LOS CONCEPTOS FUNDAMENTALES DE LA METAFÍSICA. MUNDO, FINITUD Y SOLEDAD (1929/30) DE MARTIN HEIDEGGER ${ }^{1}$
}

\author{
ENRIQUE V. MUÑOZ PÉREZ \\ Universidad Católica del Maule, Chile
}

\begin{abstract}
RESUMEN: El presente artículo busca reconstruir la discusión entre mecanicismo y vitalismo en la que se inserta Heidegger, a partir de algunas de las referencias explícitas que él hace sobre Wilhelm Roux y Hans Driesch en la lección Los conceptos fundamentales de la metafísica. Mundo, finitud, soledad 1929/30. Más específicamente, mi objetivo es reconocer y analizar las principales tesis de W. Roux y $\mathrm{H}$. Driesch. Ellas son utilizadas por Heidegger para esclarecer la esencia del animal a partir del tratamiento de la noción de «organismo».
\end{abstract}

PALABRAS CLAVE: mecanicismo, vitalismo, animal, ser humano, organismo.

\section{Genesis and Development of the Concept of Evolution}

ABSTRACT: This article seeks to reconstruct the discussion between mechanism and vitalism in which Heidegger is inserted, from some of the explicit references he makes about Wilhelm Roux and Hans Driesch in the Lesson The fundamental concepts of metaphysics. World, finitude, solitude 1929-1930. More specifically, my object is to recognize and analyze the principal thesis from W. Roux and $\mathrm{H}$. Driesch. They are used by Heidegger to clarify the essence of the animal from the treatment of the notion of "organism".

KEY WORDS: mechanism, vitalism, animal, human being, organism.

\section{INTRODUCCIÓN}

En la lección del semestre de invierno 1929/30 denominada Los conceptos fundamentales de la metafísica. Mundo, finitud, soledad de Martin Heidegger se ve parcialmente reflejado el debate biológico alemán de la segunda parte del siglo XIX y de principios del siglo xx entre biólogos mecanicistas y vitalistas, representados por Wilhelm Roux y Hans Driesch, respectivamente. ¿Por qué

1 Este artículo se enmarca en el Proyecto de Investigación de Iniciación (2011-2013) "¿Ser humano o animalidad? Tarea y alcance de Los conceptos fundamentales de la metafísica». Mundo, finitud, soledad (1929/30) que cuenta con apoyo financiero del Fondecyt (Chile) (Proyecto $\mathrm{N}^{\mathrm{o}}$ 11110127). Agradezco muy sinceramente al profesor Dr. Alejandro G. Vigo por las agudas observaciones hechas al texto. 
Heidegger se interesa en esta discusión, aparentemente, tan ajena a la reflexión filosófico-trascendental de Ser y Tiempo? ¿Es una mera presentación del «estado del arte» biológico en la que se enmarca la mencionada lección o quiere abordar Heidegger de manera filosófica algún tópico relativo a la vida? y, si esto es así, ¿qué gana Heidegger al hacerse cargo de esta problemática entre vitalistas y mecanicistas?

La finalidad del presente trabajo radica, entonces, en intentar reconstruir la discusión histórica en la que se inserta Heidegger, a partir de algunas de las referencias explícitas que él hace sobre Wilhelm Roux y Hans Driesch en la lección Los conceptos fundamentales de la metafísica. Mundo, finitud, soledad 1929/30. . Más específicamente, mis objetivos son reconocer, analizar y sacar el rendimiento filosófico de las principales tesis de los biólogos Roux y Driesch que son utilizadas por Heidegger para esclarecer la esencia del animal a partir del tratamiento de la noción de «organismo».

Deliberadamente he dejado fuera de esta presentación el pensamiento biológico de Jakob von Uexküll, porque constituye un caso paradigmático para la reflexión heideggeriana, lo que obliga a un tratamiento diferenciado.

Mi hipótesis investigativa es, en consecuencia, que Heidegger hace uso crítico de los análisis de los biólogos Roux y Driesch con un propósito filosófico: pensar radicalmente — si se prefiere, metafísicamente- el fenómeno del organismo en el marco de la carencia de mundo del animal y de la configuración de mundo del ser humano. En otras palabras, Heidegger busca tomar distancia de la concepción mecanicista de Roux sobre el organismo como «un conjunto de herramientas» y, del mismo modo, de la concepción vitalista de Driesch sobre el organismo, aunque reconoce, en este último caso, el aporte que éste hace con la «idea de todo» (Idee des Ganzen) o de "totalidad»(Ganzheit) a la comprensión del organismo como un ente que es capaz de autogenerarse y, además, a la misma noción de mundo. Uno de los aportes decisivos que realiza esta investigación sobre el organismo que desarrolla Heidegger, es que el ser humano, a diferencia del animal que es pobre de mundo, es capaz de comprender el mundo como «totalización» (Ergänzung). Por otro lado, Heidegger quiere también diferenciarse de una "filosofía de la vida» (Lebensphilosophie) o de una filosofía biológica $^{3}$ que no ha pensado los problemas hasta sus estructuras categoriales o fundamentales ${ }^{4}$.

2 Un importante referente en esta discusión es el excelente trabajo de Thomas Kessel Phänomenologie des Lebendigen. Heideggers Kritik an den Leitbegriffen der neuzeitlichen Biologie. En algún sentido, el presente trabajo se inspira en el libro de Thomas.

3 Hay que decir que el mismo H. Plessner entiende de esa manera su trabajo: «Die probleme einer philosophischen Biologie und Anthropologie, die es bahandelt, hatten sich aus konsequenter Weiterverfolgung meiner sinnesphilosophischen Untersuchungen ergeben» (Plessner 1981 9. El subrayado es mío).

4 En la lección de Marburgo Lógica. La pregunta por la verdad del semestre de invierno de 1925-1926, Heidegger toma distancia de la filosofía de la vida. «Dentro de la filosofía actual estas advertencias son importantes en la medida en que, como ustedes ya deberían saber, se ha intentado hacer frente a la filosofía de la vida, como en efecto se ha autodenominado 
El artículo se divide, entonces, en dos grandes momentos: (1) Wilhelm Roux y Hans Driesch ante el «organismo» en Los conceptos fundamentales de la metafísica. Mundo, finitud, soledad 1929/30 de Martin Heidegger y (2) Breves alcances de la relación entre metafísica y biología.

\section{Wilhelm Roux y Hans Driesch ante el «ORganismo» en los conceptos FUNDAMENTALES DE LA METAFISICA. MUNDO, FINITUD, SOLEDAD 1929/30 DE Martin Heidegger}

\subsection{Consideraciones previas}

Una de las cuestiones preliminares que supone el tratamiento que hace Heidegger de los estudios biológicos de Driesch y de Roux es metodológica: ¿cómo entender la relación entre biología y filosofía? El contexto de la discusión heideggeriana está dado por una nueva aproximación a la noción de mundo, en contraste con Ser y Tiempo y De la esencia del Fundamento, a partir de la consideración comparativa entre la piedra, el animal y el ser humano. El interés de Heidegger se focaliza en identificar las divergencias esenciales entre estos dos últimos. Si bien no es fácil establecer, por ejemplo, la diferencia entre el ser humano y el animal ${ }^{5}$, Heidegger establece un criterio orientador: en toda esta discusión, no hay que perder de vista que el interés último es metafísico.

Tenemos que poder dar información no acerca de cómo animales y hombres se diferencian en algún aspecto, sino acerca de qué constituye la esencia de la animalidad del animal y la esencia de la humanidad del hombre. (...) A su

de modo desacertado, es una filosofía biológica. Esta oposición frente a la filosofía de la vida, que ha arrancado de Rickert, se basa de entrada en este mal entendido de confundir la problemática categorial de la filosofía en lo referente a la vida con la biológica. A Rickert hay que darle la razón en tanto que, de facto, la filosofía de la vida, en sus investigaciones y resultados, en el fondo no ha llegado hasta las estructuras categoriales, pero según su propia tendencia tiene a la vista tal cosa. Que en realidad ella no se comprenda a sí misma se debe ya a la denominación de «filosofía de la vida», que en sí misma es una tautología, pues la filosofía no tiene que ver con otra cosa que con la propia existencia. Es decir, «filosofía de la vida» es algo tan agudo como «botánica de las plantas», y si aún se discute que la botánica se botánica de las plantas, entonces esta agudeza mental aún se ha superado» (HEIDEgGer 2004 175-176/GA 21 216.). En una línea similar se pronuncia Heidegger en Ser y Tiempo: «Si en la biología sobre todo, nuevamente, después de K. E: von Baer- se hace uso de esta estructura de ser, no por ello debe juzgarse como «biologismo» el uso filosófico de la misma. Porque tampoco la biología puede jamás, en cuanto ciencia positiva, encontrar ni determinar esta estructura - tiene que presuponerla y hacer constante uso de ella. Pero la estructura misma no puede ser explicitada filosóficamente, incluso como un a priori del objeto temático de la biología, si ella no ha sido previamente comprendida como estructura del Dasein» (HEIDEGGER 2009 79).

5 En otro lugar he intentado explicar las principales diferencias entre el ser humano y el animal en el marco de Los conceptos fundamentales de la metafísica. Mundo, finitud, soledad 1929/30. Cf. MuÑoz, E., "Ser humano, animal y animalidad» en: Revista Veritas, 2013, en prensa. 
vez, la animalidad del animal sólo podemos determinarla si resulta claro qué es lo que constituye la vida de lo vivo a diferencia de lo no vivo, que ni siquiera tiene la posibilidad de morir. Una piedra no puede estar muerta porque no vive (Heidegger 2007 228).

Sin embargo, para Heidegger éste no es todo el problema, porque también hay, como sostuve, cuestiones de corte metodológico que deben aclararse: "¿de qué modo puede y debe hacerse accesible la vida de lo vivo en su esencia? ¿De qué modo se nos ha de hacer accesible la vida, el ser-animal del animal y el serplanta de la planta?»(Heidegger 2007 228-9). En otras palabras la esencia del ser humano o del animal no podrá ser determinada en laboratorios ni mediante estudios morfológicos o anatómicos, tampoco mediante consideraciones teleológicas de la vida, sino mediante un esfuerzo fenomenológico: buscar un acceso original a su respectiva esencia.

De este modo, Heidegger toma la decisión metodológica de esclarecer la diferencia entre el ser humano y el animal a partir de la segunda tesis formulada, es decir, a partir de la tesis intermedia: el animal es pobre de mundo. Con ello pretende tener presente las dos tesis adicionales, esto es, la falta de mundo de la piedra y la configuración de mundo del ser humano.

Heidegger se pregunta, en consecuencia, qué tipo de tesis es «el animal es pobre de mundo». Una aproximación desde el entendimiento no especializado sostendría que la mencionada tesis proviene de la biología y, específicamente, de la zoología, puesto que es la disciplina biológica la que se encarga de estudiar los animales. Sin embargo, enfatiza Heidegger, dicho enunciado tiene un carácter esencial, es un «enunciado esencial» (Heidegger 2007 237) o, como sostiene más adelante, el enunciado sobre la carencia del animal se enmarca en una «interpretación metafísica de la vida» (Heidegger 2007 239). Esto quiere decir, según Heidegger, que la proposición «el animal es pobre de mundo» ni procede de la zoología ni puede discutirse independientemente de la zoología. «La proposición no se basta sin una determinada orientación con arreglo a la zoología y biología en general, y, pese a todo, la dirección de su confirmación no la tiene en ellas» (Heidegger 2007 237. El subrayado es mío). En otras palabras, Heidegger considera que la tesis «el animal es pobre de mundo» es un enunciado metafísico que tiene que ser entendido como presupuesto para la zoología, pero que no tiene un genuino contenido con independencia de la zoología.

¿Qué quiere decir eso? Para esclarecer estos pasajes de la lección del 29/30 es necesario tener presente el parágrafo §3 de Ser y Tiempo, donde Heidegger aborda el tema de los «conceptos fundamentales» (Grundbegriffe). El contexto de las reflexiones heideggerianas está dado por la utilidad de la investigación propuesta en la obra fundamental de Heidegger, específicamente la pregunta ¿para qué sirve volver a plantear la pregunta por el ser? Al respecto, Heidegger sostiene, preliminarmente, que ser es siempre el ser de un ente y que el todo del ente puede convertirse en "ámbito del descubrimiento y delimitación de determinadas regiones esenciales» (Heidegger 2009 30); dichas regiones esenciales, a su vez, pueden ser objeto de las investigaciones científicas específicas. Por 
ejemplo, la vida, que es una región esencial para Heidegger, puede ser estudiada particularmente a partir de la noción de «animal».

En otras palabras, el término «animal» funciona en la argumentación heideggeriana de Los conceptos fundamentales de la metafísica, Mundo, soledad, finitud como un "concepto fundamental» que tiene un carácter bifrontal, esto es, que mira tanto a la metafísica como a la biología. Heidegger define, de este modo, el mencionado concepto en Ser y Tiempo:

Conceptos fundamentales son aquellas determinaciones en que la región esencial a la que pertenecen todos los objetos temáticos de una ciencia logra su comprensión preliminar, que servirá de guía a toda investigación positiva. Estos conceptos reciben, pues, su genuina justificación y «fundamentación» únicamente a través de la previa investigación de la región esencial misma (Heidegger 2009 31. El subrayado es mío).

Probablemente se comprenda mejor ahora que la proposición «el animal es pobre de mundo", siendo un enunciado metafísico, no pueda entenderse sino en relación a la zoología y a la biología. Es decir, ciertamente el preguntar ontológico o metafísico es más originario que el preguntar de la ciencia que estudia los animales, pero inversamente las investigaciones científicas sobre el animal ayudan a que el Dasein se autoesclarezca ${ }^{6}$. He ahí la bifrontalidad de los «conceptos fundamentales».

Hay, entonces, una continuidad en este punto entre la lección de Los conceptos fundamentales de la metafísica. Mundo, finitud, soledad y el proyecto de Ser y Tiempo. La metafísica - la ontología fundamental de Ser y Tiempo- es vista precisamente como la base de todas las ciencias particulares y ontologías regionales. Es decir, si bien en la lección del año 29/30 Heidegger toma en consideración las ciencias particulares como la biología, lo que constituye una diferencia con Ser y Tiempo ${ }^{7}$, no renuncia al carácter prioritario de la ontología fundamental. El matiz que introduce Heidegger en la mencionada lección es que la relación entre filosofía y ciencia, tiene que entenderse de la siguiente manera: «una produce conceptos fundamentales, la otra aporta hechos». (Heidegger 2007 pág. 241. El subrayado es mío) Pero, en el fondo, estas afirmaciones no contradicen en nada la argumentación de Ser y Tiempo. De hecho,

6 «La pregunta por el ser apunta, por consiguiente, a determinar las condiciones a priori de la posibilidad no sólo de las ciencias que investigan el ente en cuanto tal o cual, y que por ende se mueven ya siempre en una comprensión del ser, sino que ella apunta también a determinar la condición de posibilidad de las ontologías mismas que anteceden a las ciencias ónticas y las fundan» (HeIDEgGer 2009, p. 32). Al respecto, véase el artículo de A. Vigo, «Tenencia previa y génesis ontológica. Observaciones sobre algunas estrategias metódicas en la analítica existenciaria de Sein und Zeit», en: Heidegger hoy. Estudios y perspectivas, editado por Alfredo Rocha, Grama Ediciones, Editorial Bonaventuriana, Buenos Aires/Bogotá, 2011, 257-303.

7 Hay que recordar que el parágrafo $\$ 10$ de Ser y Tiempo se denomina «Delimitación de la analítica del Dasein frente a la antropología, la psicología y la biología». Cf. HeIDEgGer, M, Ser y Tiempo, traducción de Jorge E. Rivera, Editorial Trotta, Madrid, 2009, 66. 
Heidegger afirma sobre la ciencia en Los conceptos de la metafísica. Mundo, finitud, soledad que «la tomamos más bien como una posibilidad existencial de la existencia humana» (Heidegger 2007 242), es decir, como una de las posibilidades que el ser humano puede llevar a cabo o no llevar a cabo. La biología, entonces, es una ciencia fundada en la ontología del Dasein ${ }^{8}$. De este modo, hay que leer la pregunta por la esencia del animal, por la esencia del ser humano o la discusión con los mecanicistas y vitalistas desde una mirada metafísica, en el caso de Los conceptos de la metafísica. Mundo, finitud, soledad ${ }^{9}$.

Por otro lado, el debate entre mecanicistas y vitalistas emerge en medio de la defensa que hace Heidegger de la biología. Ella debe ser liberada de la «tiranía» de la física y de la química, porque «en lo fundamental, desde estas disciplinas la "vida" no puede comprenderse en cuanto tal" (Heidegger 2007 239). La biología, en la época de Heidegger, está renovando sus bases, esto es, está tomando distancia tanto del mecanicismo como del vitalismo.

O diciéndolo desde otro aspecto que no coincide sin más con lo que acabamos de decir, hoy se trata de liberarse de la concepción de la vida como un mecanismo. Esta tendencia negativa venía guiada todavía hasta hace poco por el lema: lucha contra el mecanismo, vitalismo, consideración teleológica de la vida. Esta consideración de la vida está tan cargada de grandes mal entendidos como la concepción mecanicista de la vida (Heidegger 2007 239. El subrayado es mío).

El problema es, entonces, que ni la perspectiva mecanicista ni la vitalista son capaces de alcanzar, a juicio de Heidegger, la esencia del animal. Hay que esperar, eso sí, un tanto para entender de mejor manera los alcances de estos postulados heideggerianos. Previamente hay que dejar de lado estas consideraciones metodológicas y volver sobre la tesis intermedia formulada por Heidegger: «el animal es pobre de mundo».

\subsection{W. Roux y el organismo como "conjunto de herramientas»}

La explicación de la tesis intermedia con la que Heidegger busca abordar de manera comparativa el tema del mundo en Los conceptos fundamentales de

8 De hecho, así lo sostiene Heidegger en Ser y Tiempo: «En el orden de su posible comprensión e interpretación, la biología como "ciencia de la vida" se funda en la ontología del Dasein, aunque no exclusivamente en ella. La vida es un modo peculiar de ser, pero esencialmente sólo accesible en el Dasein» (HEIDEGger 2009 71).

9 Quisiera enfatizar todavía sobre este punto que cuando Heidegger aborda la discusión entre vitalistas y mecanicistas no tiene un interés inter- o transdisciplinar, es decir, no está poniendo en el mismo nivel a la metafísica que a la biología. Como ya se ha dicho, Heidegger no quiere hacer filosofía de la biología, aunque, quizás, esboce una reflexión sobre la ciencia natural. Más bien, él se hace cargo, desde su proyecto trascendental o fundamental, de aquellos elementos de la discusión biológica de su época que puedan mejorar, profundizar o confirmar sus planteamientos o, si se prefiere con palabras de Heidegger, la más investigación de la biología de su época tiene que ser leída «con mirada filosófica» (HeIdEgGer 2007 243). Por ejemplo, el concepto de «medio ambiente» en J. von Uexküll. 
la metafísica. Mundo, finitud, soledad, es desarrollada a partir de la noción de "pobreza» (Armut). La argumentación de Heidegger es conocida, por lo que no la desplegaré detalladamente, puesto que mi objetivo, en esta parte del trabajo, es identificar las tesis de Roux y Driesch en la lección de Heidegger y, desde allí, profundizar en algunas de sus obras fundamentales.

Con todo, es necesario decir un par de palabras referidas a la tesis «el animal es pobre de mundo». La mencionada afirmación supone, en un primer acercamiento, que el animal carece de algo o tiene algo de menos, en contraste con el ser humano que sería sobreabundante o rico de mundo ${ }^{10}$. Pero al analizar más finamente el comportamiento del animal, es posible sostener, aunque suene paradójico, que el animal «tiene y no tiene mundo». Heidegger lo ejemplifica de la siguiente manera: la abeja tiene su colmena, panales, flores, otras abejas y su reina. Sin duda alguna, la abeja «tiene» mundo, puesto que se relaciona con otros entes que no son ella misma. Sin embargo, la abeja «no tiene mundo», en el sentido que no puede referirse a dichos entes «en tanto que» (als) entes. La abeja no trata con el pistilo de las flores en cuanto pistilo ni a sus compañeras de colmena en tanto que otras abejas.

Esta aparente ambigüedad respecto de la tesis sobre la pobreza de mundo del animal es abordada por Heidegger recurriendo a la biología, aunque teniendo presente lo dicho respecto de los «conceptos fundamentales»:

Justamente este esfuerzo, la caracterización exclusivamente propia de la animalidad, no hemos de eludirlo. Pero significa que tenemos que emprender la tarea de una determinación esencial de lo viviente, la caracterización de la esencia de la vida, si bien en atención especial al animal. (...) Aun cuando renunciemos a preguntas especiales, sin embargo tenemos que buscar consejo en las tesis fundamentales de la zoología sobre la animalidad y la vida (Heidegger 2007 262. El subrayado es mío).

Heidegger, a continuación, no va a tematizar la «vida» en sí misma, sino que la va tratar específicamente a partir del tema de la animalidad. Él comienza su acercamiento a las principales tesis de la zoología sobre la animalidad y la vida de un modo negativo, es decir, cuestionando la concepción del organismo como herramienta de Wilhelm Roux. No obstante lo anterior, el tema del organismo es introducido por Heidegger de una manera etimológica:

Organismo es aquello que tiene órganos. "Órgano» viene del griego

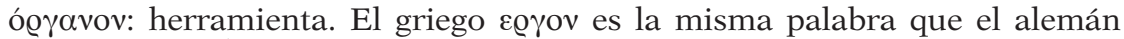
Werk, «obra». Órgano es la herramienta, el utensilio de obrar. Por eso uno de los biólogos dirigentes de la época moderna, Wilhelm Roux, define el organismo como un complejo de herramientas. Es decir, el organismo mismo es,

10 Kessel nos informa que la diferencia entre «riqueza del ser humano» $\mathrm{y}$ "pobreza del animal» proviene del trabajo biológico de F.J.J. Buytendijk en un artículo titulado «Zur Untersuchung des Wesensunterschieds von Mensch und Tier»: «Der Mensch hat im intelligenten Akt das "Andere" (...) Das Tier "hat" nichts als das Notwendige — seine Umwelt—, d.h. es ist arm. Der Mensch hat mehr als er braucht —seine Welt—, d.h. es ist reich». Cf. KesseL, T., $2011,144$. 
como podemos decir, una herramienta «complicada», complicada en tanto que las diversas partes están entramadas entre sí, de modo que aportan un logro global unitario (Heidegger 2007 264. El subrayado es mío).

Más allá de las conocidas etimologías de «organismo» y «órgano», me parece necesario esclarecer los supuestos de la afirmación de Heidegger según la cual Roux define el organismo como un «conjunto de herramientas».

Wilhelm Roux (1850-1924) es un biólogo mecanicista alemán considerado como fundador de la «mecánica del desarrollo» (Entwicklungsmechanik) del organismo, entendiendo por ella «la ciencia de la composición y las reacciones de aquellas combinaciones de energía, que producen desarrollo» (Roux $18954)^{11}$. En otras palabras, la mecánica del desarrollo del organismo es una ciencia analítico-causal, la que mediante la división en laboratorios de diversas estructuras del organismo en sencillas frecuencias de estructura pretende, aplicar dichos resultados a casos regulares de la naturaleza y con eso tener un medio para poder evidenciar la combinación de las mismas bajo la consideración de relaciones causales. ${ }^{12} \mathrm{El}$ más célebre de los experimentos de Roux fue el aislamiento de los blastómeros de un cigoto de rana; Roux observó que ambas mitades seguían desarrollándose de manera independiente, dando lugar a embriones.

Hecha esta aclaración, volvamos a la lección de Heidegger. Como se sostuvo más arriba, Roux define el organismo como un complejo de herramientas o como una herramienta complicada, en la que diversas partes están entramadas entre sí, de modo que aportan a un logro global unitario. Sin embargo, Heidegger se pregunta: «¿Pero en qué se diferencia entonces el organismo de una máquina? (...) ¿Qué sucede ahora con la relación de los tipos de ente que acaban de aparecer: el utensilio, la herramienta, la máquina, con eso que llamamos mundo?»(Heidegger 2007 264) Heidegger afirma al respecto que entes como el utensilio, la herramienta o la máquina se encuentran en un lugar intermedio entre la piedra y el animal. Como se ha dicho, la piedra no tiene mundo, el animal es pobre de mundo y el utensilio, la herramienta o la máquina «son sin mundo, pero al mismo tiempo, en tanto que sin mundo, pertenecen al mundo» (Heidegger 2007 264. El subrayado es mío). Esto quiere decir, recordando las reflexiones del \$15 de Ser y Tiempo, que el utensilio y, en especial, la máquina son producto del hombre y a dichos entes subyace la configuración de mundo ${ }^{13}$.

11 «Die Entwicklungsmechanik im allgemeineren Sinne ist, mit Bevorzugung ihres kinetischen Theiles, als die Wissenschaft von der Beschaffenheit und den Wirkungen derjenigen Combinationen von Energie zu bezeichnen, welche Entwicklung hervorbringen» (Roux 1895, p. 4).

12 Cf. Kessel, T., 2011, p. 104 ss.

13 ¿Qué quiere decir «configuración de mundo»? Heidegger aclara que esta expresión es polisémica. Significa "producir» el mundo, «dar una imagen» suya, «representárselo», abarcarlo, etc. En otras palabras, el ser humano no sólo produce artefactos o construye puentes, sino que forma con otros seres humanos su historia, su tiempo y su época o, si se prefiere, 
Si esto es así, la concepción de Roux del organismo como «complejo de herramientas» es considerada insuficiente por Heidegger. Para ello, él distingue y analiza las diferencias entre «máquina» (Maschine), «utensilio» (Zeug) y «herramienta» (Werkzeug) ${ }^{14}$, sosteniendo la tesis que ni la máquina es idéntica a la herramienta ni la herramienta al utensilio. De este modo, utilizando el ya clásico ejemplo de Ser y Tiempo, Heidegger sostiene que el martillo es una herramienta, un utensilio en general, "algo de cuya esencia forma parte servir para algo. Según su carácter propio de ser, es "algo para..." [etwas, um zu ...]» (Heidegger 2007 265. El agregado es mío). Todo utensilio es aquello que es sólo en una conexión, que está determinada en cada caso por la totalidad de la situación. El martillo, por consiguiente, como herramienta nos sirve para clavar y hacer una mesa, pero también nos puede servir para destruir algo. Piénsese en lo útil que es un gran martillo, un mazo, para derribar una puerta. Con todo, agrega Heidegger, no todo utensilio es una herramienta en sentido estricto. Por ejemplo, el lápiz es un utensilio de escritura o el monociclo es vehículo, pero ambos no son máquinas. En consecuencia, para Heidegger «no todo utensilio es una herramienta, ni menos aún toda herramienta y todo utensilio es una máquina» (Heidegger 2007 265).

Lo anterior lleva a concluir a Heidegger que la posición de W. Roux es equivocada. Aun cuando toda máquina es un utensilio, eso no significa que sea una herramienta. De este modo, ni la máquina es idéntica a la herramienta ni la herramienta al utensilio.

Por eso, es imposible de entrada tomar la máquina como un complejo de herramientas o como una herramienta complicada. Y si además el organismo es totalmente distinto de la máquina, como ésta del utensilio, entonces la definición del organismo como un complejo de herramientas se desmorona. (Y sin embargo es la definición por parte de un investigador tan meritorio como Roux, «Mecánica del desarrollo») (Heidegger 2007 265-6. El subrayado es mío).

En dos palabras, la crítica de Heidegger a la noción de organismo que maneja el mecanicismo estriba en que la teoría y la investigación mecanicista de la vida, que ha tomado a la célula como elemento primigenio de lo viviente, «ha tratado de componer a partir de ella el organismo, primeramente desconocido en su esencia y destruido en un montón de fragmentos, considerando además la célula misma de modo físico-químico» (Heidegger 2007 376. El subrayado es mío).

Si ésta es entonces la crítica de Heidegger a la visión mecanicista del organismo, ¿cuál es su posición frente al organismo? Teniendo presente que el organismo no es una mera máquina, Heidegger busca esclarecer la pregunta

lleva a cabo sus proyectos. Cf. HeIDEgGER, M., Los conceptos fundamentales de la metafísica. Mundo, finitud, soledad, 344/GA 29/30, 414.

14 Hay que decir que en nuestra lengua no se aprecia la relación que existe entre términos como «utensilio» y "herramienta», en comparación a los correspondientes conceptos alemanes «Zeug» $\mathrm{y}$ «Werkzeug». 
planteada a partir de la diferenciación entre el «órgano» (Organ) y el «utensilio» (Zeug). La comparación puede establecerse, por ejemplo, entre la piel y una rasuradora desechable. Si bien tanto la piel como la rasuradora sirven para algo, una para cubrir nuestros huesos, músculos y órganos internos y la otra para afeitarnos, tienen una diferencia decisiva: la piel como órgano de nuestro cuerpo humano tiene la peculiaridad de generarse regularmente ${ }^{15}$, en cambio, la rasuradora la desechamos una vez que su filo se estropea; ésta, de esa manera, ha completado su utilidad. Otra diferencia radica en que la piel es «mi piel» y no de otro, en cambio, la rasuradora es un ente «al alcance y al uso de varios y diversos hombres» (Heidegger 2007 270). De paso, estas reflexiones de Heidegger sobre las diferencias entre el utensilio y el órgano, alcanzan también a la «máquina» (Maschine). La máquina precisa de un constructor distinto de ella, el ser humano, que no sólo la construye, sino que establece también sus instrucciones de funcionamiento. La máquina, por ejemplo un auto, no puede ajustarse y reajustarse a sí mismo en su funcionamiento, puesto que necesita del mecánico para ser reparada. Por el contrario,

El organismo, dentro de ciertos límites, se reestablece y se renueva a sí mismo. Producción de sí mismo [Selbstherstellung] en general, conducción de sí mismo [Selbsleitung] y renovación de sí mismo [Selbsterneuerung] son evidentemente momentos que caracterizan al organismo frente a la máquina, y que al mismo tiempo dan una visión de las direcciones peculiares en las que es capaz y está capacitado como organismo. (Heidegger 2007 274. El subrayado y los agregados son míos) ${ }^{16}$.

Heidegger, en todo caso, es consciente del peligro que una definición del organismo, en los términos antes mencionados, encierra: la interpretación vitalista ${ }^{17}$. Para evitarla, él recurre a las más recientes investigaciones biológicas sobre las amebas desarrolladas por Jakob von Uexküll, con el objetivo de

15 Resuena en esta caracterización heideggeriana del organismo, las observaciones hechas por Kant en la Crítica del Juicio, Segunda Parte, §65. "Así como en un producto semejante de la naturaleza, cada parte existe sólo mediante las demás, de igual modo es pensada como existente sólo en consideración de las demás y del todo, es decir, como instrumento (órgano); pero eso no basta (pues pudiera ser también instrumento del arte, y entonces ser representada posible, sólo como fin, en general), sino que ha de ser pensada además como un órgano productor de las otras partes (por consiguiente, cada una a su vez de las demás), tal como no puede serlo ningún instrumento del arte, sino no sólo de la naturaleza, la cual proporciona toda materia para instrumentos (incluso del arte), y sólo entonces y por eso puede semejante producto, como ser organizado y organizándose a sí mismo, ser llamado un fin de la naturaleza» (KANT 1995 345).

${ }_{16}$ Me permito también corregir, por una cuestión de comprensión del texto, la traducción de A. Ciria en lo que respecta a los términos alemanes "Selbstherstellung», "Selbsleitung» $\mathrm{y}$ «Selbsterneuerung».

17 «Frente a esos intentos de esclarecer la esencia del organismo, que se han difundido sobre todo en el llamado vitalismo a diferencia del mecanicismo, se trata de dejar abierta la pregunta de si y en qué medida, en atención a las circunstancias mencionadas de - como decimos- la autogeneración, autoconducción y autorenovación, puede esclarecer la conexión esencial entre la capacidad del organismo y los órganos» (HEIDEgGer 2007 274). 
mostrar la relación entre órgano y organismo. Con todo, el tratamiento específico de este punto será materia de un próximo artículo ${ }^{18}$.

Respecto de la noción de organismo que desarrolla Heidegger, me resta finalmente tratar dos puntos brevemente: la distinción entre la «capacidad» (Fähigkeit) del órgano y la «el estar preparado o estar listo» (Fertigkeit) ${ }^{19}$ para algo del utensilio, y la conexión entre capacidad e impulso como preámbulo de la determinación de la esencia del animal como «inmersión» o «focalización» (Benommenheit $)^{20}$. Sobre el primer punto, Heidegger subraya que el órgano y el utensilio ofrecen posibilidades que son distintas. Su modo de ser, como se ha dicho, se diferencia como la «capacidad del órgano» y como el «estar listo o preparado del utensilio. Heidegger ilustra esta diferencia mediante los ejemplos de la pluma, como utensilio, que está lista o preparada para que alguien la use para escribir, pero que no es capaz de escribir por sí misma y el ojo que, en tanto que órgano, no es capaz de ver, sino que cobra su sentido en el organismo. «La capacidad se crea sus órganos determinados» (Heidegger 2007 279).

La tarea en que se empeña Heidegger es ahora avanzar desde la estructura interna de la capacidad, hasta la esencia del organismo. Se encuentra entonces en los albores de la determinación de la esencia de la animalidad. En otras palabras, la capacidad es constitutivo del modo de ser del animal. Sobrepasa la intención de este trabajo desarrollar esta idea, sin embargo, para cerrar esta presentación que tenía como tarea mostrar la manera en que Heidegger presenta y discute las tesis de Roux en la lección del 29/30, es interesante mencionar una última referencia de Heidegger antes de pasar a las reflexiones de Driesch.

Heidegger cierra su análisis sobre el órgano y el utensilio, diciendo sobre éste último que queda sometido a una cierta "prescripción» (Vorschrift) o determinación, en el sentido que un lápiz tiene como tarea el servir para escribir o la rasuradora para afeitarse. En cambio, el órgano que se inserta en un organismo, «lo capaz [Das Fähige], (...), no está sometido a una prescripción, sino que ello mismo aporta reglas y regula [regelmitbringend und regelnd]. Se impulsa a sí mismo [Es treibt sich selbst], de un modo determinado, hacia su ser capaz de ... [in sein Fähigsein zu ... vor]» (Heidegger 2007 280. El agregado es mío) Esta es una de las claves interpretativas para comprender la esencia del animal, puesto que el animal tiene un conjunto de capacidades que lo caracterizas. Él tiene la «capacidad» de ver, de atrapar, de digerir, de cazar, de reproducirse, etc.

18 Cf. Kessel, T., 2011, 160 ss.

19 Discrepo acá con la traducción de A. Ciria, quien traduce el término «Fertigkeit»como «disposición». Me parece que la expresión «estar preparado» o «estar listo» recoge mejor el sentido de las expresiones de Heidegger. Hay que recordar que el adjetivo alemán "fertig» significa «terminado», «acabado» o «listo».

20 Me permito discrepar nuevamente con la traducción de A. Ciria, en relación a la traducción de la noción de «Benommenheit». Considero que dicha expresión debiera traducirse como «inmersión» o "focalización» y no como "perturbarmiento» o "atontamiento», porque "sich benehmen» apunta al modo de comportarse del animal que no es atontado o perturbado, sino que «concentrado» o «inmerso» en un radio de acción determinado. 


\subsection{H. Driesch y el organismo como «totalidad»}

La presencia de Hans Driesch en la lección de Heidegger se concentra principalmente en el §61, donde Heidegger se refiere a los, a su juicio, «pasos decisivos» (Heidegger 2007 316) o paradigmas fundamentales de la biología alemana contemporánea: Hans Driesch y Jakob von Uexküll. Como ya sostuve, dejaré para una próxima oportunidad el tratamiento del biólogo von Uexküll, por lo que me concentraré en el aporte de la biología de Driesch al pensamiento de Heidegger.

Hans Driesch es un filósofo y biólogo alemán (1867-1941), discípulo de W. Roux, cuya pretensión filosófica queda en evidencia en el título de una de sus obras principales: «Filosofía de lo orgánico» (Philosophie des Organischen). En esta serie de lecciones magistrales denominadas Gifford-Vorlesungen —que Driesch dictó entre los años 1907 y 1908 en la Universidad de Aberdeen, Escocia - él sostiene que la meta de las mencionadas lecciones «no es un libro de texto de biología teórica, sino que incluye una interpretación sistemática de aquella doctrina biológica, que es conocida con el significado de verdadera filosofía de la naturaleza» (Driesch 1909 1) ${ }^{21}$. Específicamente, las lecciones concentran las reflexiones de Driesch sobre lo orgánico. La apuesta de Driesch es, entonces, que las ciencias naturales alcanzan su significado real al estar en contacto con la filosofía ${ }^{22}$, en otras palabras, Driesch intenta llevar a la biología "de una ciencia ingenua hacia un sector real de la filosofía de la naturaleza» (Driesch 19095 5) $^{23}$ o hasta, incluso más, ella tiene que «estar al servicio de la filosofía»(Driesch 1909 15)24. Esto implica repensar la naturaleza misma de la biología, en manos de la corriente mecanicista. A juicio de Driesch, la biología no puede «hacer» vida, como un físico produce electricidad o un químico conexiones de carbono, sino que tiene una aspiración superior. Ella está llamada, más bien, a ser la principal ciencia de la naturaleza, específicamente, «la biología depende de la particularidad del objeto viviente, como ella existe en la naturaleza» (Driesch 1909 11) ${ }^{25}$.

¿Cuáles son, entonces, a juicio de Heidegger, los aportes principales que Driesch para su investigación? Él considera que la contribución principal de Hans Driesch radica en el conocimiento del «carácter de totalidad del

21 «Dieses Werk ist kein Lehrbuch der theoretischen Biologie; es enthält eine systematische Darlegung derjenigen biologischen Lehren, welche für wahre Naturphilosophie von Bedeutung sind» (Driesch 1909 1).

22 «Nur mit Hilfe der Philosophie oder, besser gesagt, durch beständige Berührung mit der Philosophie können die Naturwissenschaften eine wirkliche Bedeutung für das gewinnen, was man am einfachsten die Wissenschaft von der Natur nennen könnte» (DRIEsch 1909 3).

${ }^{23} «(. .$.$) von einer naiven Wissenschaft zu einem wirklichen Zweige der Naturphiloso-$ phie (...)» (DRIESCH 1909 5).

${ }^{24}$ «Unsere Biologie wird nicht Selbstzweck sein, sondern im Dienst der Philosophie stehen» (DRIESCH 1909 15).

25 «Der Biologie hängt ab von der Sonderheit der lebenden Objekte, wie sie in der Natur vorkommen» (DRIESCH 1909 11). 
organismo» (Ganzheitcharakters des Organismus) o también llamada «idea de totalidad»(Idee des Ganzes). La totalidad significa que «el organismo no es una suma, no está compuesto de elementos y partes, sino que el hacerse y la construcción del organismo están guiados en cada uno de sus estadios por su totalidad misma» (Heidegger 2007 316).

Heidegger, de hecho, sintetiza a grandes rasgos la investigación de Driesch en la lección del 29/30. Él afirma que Driesch dedujo su teoría sobre el carácter de totalidad del organismo, a partir de sus investigaciones con los embriones de erizo de mar.

La determinación de un grupo de células del embrión como su destino posterior se realiza en el contexto del conjunto y en consideración a este conjunto. Pero una vez que se ha producido, entonces el desarrollo prosigue, con independencia del medio circundante, en la dirección que ya se había emprendido. Vemos aquí la clara irrupción de la idea de conjunto: la totalidad como factor determinante. (Heidegger 2007 316-317)

Vale la pena profundizar un poco en los planteamientos de Driesch resumidos por Heidegger, porque tuvieron gran influencia sobre la concepción del organismo y la noción de desarrollo. Hay que sostener, en primer lugar, que Driesch comenzó sus investigaciones sobre los erizos de mar en el año 1891. En dicho año, él logró separar en un pequeño tubo de vidrio erizos de mar, más precisamente, desprender las primeras celúlas segmentadas unas de otras, sin deteriorarlas. La célula segmentada aislada se siguió desarrollando, se tradujo en una media imagen segmentada, una media esfera cóncava, la que más tarde se transformó en una esfera completa y redonda, que incluía una lava formada de erizo de mar. A partir de estos resultados, Driesch se distanció de las explicaciones e investigaciones de Roux sobre embriones. De este modo, «la capacidad descubierta por Driesch, mediante estos experimentos, de determinados tipos de embriones de una "regulación de conexiones de totalidad" mediante efectos de alteración (...) determinó el conjunto de su siguiente trabajo experimental y teórico» (Mocek 1974 112) ${ }^{26}$. Driesch expuso estos resultados de su investigación en el texto La localización de procesos morfogenéticos (1899), que son retomados en las ya mencionadas lecciones Gifford. A Driesch le interesa sobremanera sostener que el concepto de «totalidad» se erige como un concepto distinto y opuesto a la de «finalidad» (Zweckmässigkeit). En una versión posterior, abreviada y parcialmente trabajadad, de Philosophie des Organischen del año 1928, Driesch sostiene que «nosotros queremos emplear esta palabra "relación de totalidad" de hecho en lugar de "orientación final", "determinado", "teleológico", "final”, etc.» (Driesch 1928 367) 27. Driesch desarrolla, entonces,

26 «Die von Driesch durch diese Experimente entdeckte Fähigkeit bestimmter Keimarten zur "ganzheitsbezogenen Regulation" nach Störungseinflüssen (...) betimmte seine gesamte weitere experimentelle und theoretische Arbeit» (Mосек 1974 112).

27 «Dieses Wort "ganzheitsbezogen" wollen wir nun also in der Tat an Stelle von "zweckmässig“, "zielstrebig”, "teleologisch”, "final”, usw. verwenden» (DRIEsch 1928 367). 
un neovitalismo, es decir, una nueva manera de comprender en la investigación biológica conceptos como los de «entelequia» o «finalidad».

Precisamente este es el punto donde Heidegger toma distancia de los positivos aportes de Driesch y lo califica como neovitalismo. «El vitalismo es tan peligroso para los problemas biológicos como el mecanicismo. Mientras que éste no permite que aflore una pregunta por la tendencia a fin, el vitalismo ataja este problema demasiado pronto» (Heidegger 2007 317) Específicamente, Heidegger considera que las investigaciones de Driesch no valoran lo suficiente la relación del organismo con el medio ambiente. En otras palabras, si tenemos presente que la determinación esencial del organismo, según Heidegger, es el perturbamiento, vemos aquí que aunque el organismo se toma como totalidad, sin embargo se lo toma de tal modo que la relación con el medio circundante no queda recogida en la estructura fundamental. «El conjunto del organismo en cierta manera se identifica con la superficie de la corporalidad animal» (Heidegger 2007 317).

Dicho lo anterior, me concentro en sacar algunos rendimientos filosóficos de los planteamientos de Heidegger sobre el organismo y su relación con el vitalismo y el mecanicismo.

\section{BREVES ALCANCES DE LA RELACIÓN ENTRE METAFÍSICA Y BIOLOGÍA}

Considero necesario terminar este trabajo tratando de mostrar el rendimiento filosófico que tiene la aproximación de Heidegger al mecanicismo de Roux y al vitalismo de Driesch. En otras palabras, procuro responder a la pregunta: ¿por qué Heidegger recurre al debate entre mecanicistas y vitalistas para explicar la tesis sobre la pobreza de mundo del animal?, es decir, ¿por qué recurre a la biología para clarificar un problema metafísico?

Las ganancias, me parece, no tienen que perder de vista que la relación entre metafísica y biología está mediada, como ya se dijo, por los «conceptos fundamentales». Dos me parecen los principales réditos de la recepción de Heidegger del debate mecanicismo y vitalismo:

a) Establecimiento de un concepto de «organismo» más complejo que el de mecanicistas y vitalistas, inspirado por los estudios de Jakob von Uexküll. Un concepto de organismo, que aunque suene raro, tiene bases metafísicas. El organismo, a juicio de Heidegger, es capaz de autogenerarse dado que tiene capacidades para ello. El organismo es mucho más que un conjunto de herramientas o la asociación de partes. Es una totalidad que tiene una relación con el medio ambiente en el que se encuentra. En dicho medio ambiente, el organismo - por ejemplo un animal- es un todo que satisface sus necesidades de alimentación o reproducción. Para ello, el animal tiene capacidades de ver, de atrapar, de digerir, de cazar, de reproducirse, etc. Sin embargo, las capacidades del animal no son ilimitadas, puesto que éste no es capaz de ir más allá del anillo en que se encuentra circunscrito. A ello denomina Heidegger «focalización» o «inmersión» en 
el medio ambiente. En dos palabras, el animal es una totalidad de cierto tipo, tiene entorno, pero no es capaz de «totalización» (Ergänzung). Con esta conclusión, Heidegger toma distancia de las caracterizaciones que ven entre el animal y el ser humano en variantes psicofísicas y biológicas al modo de Scheler o de Plessner.

b) En Ser y Tiempo aparece el «algo como algo» vinculado al «por-mor-de» (Worumwillen ${ }^{28}$. Sin embargo, en Los conceptos fundamentales de la metafísica. Mundo, finitud, soledad Heidegger va más allá a lo que él denomina la «totalización» (Ergänzung). Para comprender este aporte de Heidegger tenemos que esclarecer brevemente la relación entre los estudios sobre el lógos, el ser humano y la tesis de la configuración del mundo. Uno de los indicadores que provienen de este análisis es la «vinculatoriedad» (Verbindlichkeit). En términos sencillos, el ser humano mediante el uso de su lógos se vincula con o se abre a lo ente. El lógos tiene la potencia y la posibilidad, fundada en la libertad del ser humano, de sostener que un ente es verdadero o falso, es decir, tiene la posibilidad de asignar el desencubrimiento o el ocultamiento del ente. Esta capacidad de vincularse con el ente no es una cuestión añadida, sino que forma parte de sí. Se va clarificando, paulatinamente, la diversidad esencial entre el estar abierto del animal y la apertura al mundo del ser humano. Un segundo indicador, está constituido por la «totalización» (Ergänzung). El ser humano se relaciona con los entes en su conjunto o de modo completo. El ejemplo de Heidegger tiene que ver con la ubicación de una pizarra en la sala de clases, que normalmente debe estar detrás del profesor. Heidegger se pregunta por qué nos parece extraño que dicha pizarra se encuentre en una esquina; por qué decimos que la «pizarra está mal ubicada». Para él, como ya se dijo, nos relacionamos con el todo que denominamos «sala de clases». Este conjunto constituye el entorno en el que nos movemos o en el que nos encontramos habitualmente. Siguiendo el ejemplo de Heidegger, por qué nos incomoda que los libros de la biblioteca de la universidad estén en el suelo, porque ellos habitualmente se encuentran en los anaqueles. En consecuencia, a partir de la «vinculatoriedad» y de la «totalización» es posible para el ser humano pronunciarse sobre el ente o, si se prefiere, tener una comprensión totalizadora del ente, cuestión de la que está privada el animal.

\section{Bibliografía}

Driesch, H. Philosophie des Organischen, Gifford-Vorlesungen. Gehalten an der Universität Aberdeen in den Jahren 1907-1908. Leipzig: Editorial de Wilhelm Engelmann, 1909. Cuarta edición, 1928.

$28 \quad \mathrm{Al}$ respecto véase el $\$ 18$ de Ser y Tiempo. 
Heidegger, M. Los conceptos fundamentales de la metafísica. Mundo, soledad y finitud, traducción de Alberto Ciria, Madrid: Alianza Editorial, 2007.

Heidegger, M. Ser y Tiempo, traducción de Jorge E. Rivera, Madrid: Editorial Trotta, 2009.

HeIDEgger, M. Lógica. La pregunta por la verdad, traducción de J. Alberto Ciria, Madrid: Alianza Editorial, 2004.

HeIdegger, M. Logik. Die Frage nach der Wahrheit, hrsg. von Walter Biemel, GA 21, Frankfurt a. M.:Vittorio Klostermann, 1976.

Kant, I. Crítica del juicio, trad. de Manuel García Morente, Madrid: Editorial Espasa Calpe, 1995.

Kessel, T. Phänomenologie des Lebendigen, Freiburg: Editorial Karl Alber, 2011.

Moceк, R. Wilhelm Roux-Hans Driesch. Zur Geschichte der Entwicklungsphsysiologie der Tiere („Entwicklungsmechanik“), Jena: Editorial Veb Gustav Fischer, 1974.

Plessner, H. Die Stufen des Organischen und der Mensch, hrsg. von Günter Dux, Odo Marquard und Elisabeth Ströker, GS IV, Frankfurt a. M.:Suhrkamp Verlag, 1981.

Roux, W. Gesammelte Abhandlungen über Entwicklungsmechanik der Organismen, Band II, Leipzig, 1895.

Universidad Católica del Maule

ENRique V. Muñoz Pérez

Departamento de Filosofía

Casilla 617 - Talca (Chile)

enmunoz@ucm.cl.

[Artículo aprobado para publicación en diciembre de 2014] 